\title{
Post-Surgical Prosthetic Rehabilitation of a Patient after Partial Maxillectomy: A Clinical Case Report
}

\author{
A Nehir Özden, Mohammed Abujalala*, Ammar Kayssoun and Şifa Atabek \\ Department of Dentistry, Near East University School of Dentistry, Turkey
}

Submission: December 28, 2018; Published: January 04, 2019

*Corresponding author: Mohammed Abujalala, Near East University School of Dentistry, Turkey

Abstract

This clinical case report describes a method for prosthetic rehabilitation of a patient with malignant cancer of the palate following partial maxillectomy. These findings suggest that an obturator significantly contributes to minimizing postoperative complications and improving the quality of life of maxillectomy patients. In prosthetic treatment, the satisfaction of the patient is related to great understanding and cooperation of the dentist with regard to gaining the necessary confidence of the dentist.

Keywords: Palatal obturator; Rehabilitation; Aesthetics; Delayed surgical obturator

\section{Introduction}

Maureen [1] clarified that treatment for head and neck cancers has evolved in the last few decades with multiple modality treatments, including radiation and chemotherapy, to improve regional and local disease control, preserve anatomic structures, reduce distant metastasis, and enhance quality of life and overall survival. He also viewed surgery as the first preferred choice for early cancers as well as cancers unresponsive to chemotherapy and radiation and in the salvage form. However, according to Kantas \& Rogers [2] surgery can result in psychological, functional and cosmetic impairment and therefore severely impacting the quality of life for patients. On the other hand, Moser et al. [3] emphasized that rehabilitation goals are focused on the restorative, supportive, palliative and preventive aspects of treatment.

Keyf [4] indicated that advanced cancers or trauma destroy structures, which include hard and soft tissues of jaws, oral tissues, facial skeleton, cheeks, lips, eyes, nose and can negatively affect the maxillofacial region. Keyf [4] remarked that the main objectives of maxillofacial rehabilitation and prosthetics are to construct a prosthesis to cure the defect, improve the function, enhance esthetics, engage the patient in society, and in doing so improve the spirit of the cancer patient, thus contributing to his/ her quality of life.

McGregor [5] suggested that there are three main types of maxillectomy: maxillectomy with loss of orbital support; maxillectomy with preservation of the orbital floor; and maxillectomy with orbital exenteration and ethmoidectomy. Rodrigues [6] highlighted that the selection of rehabilitation depends on the site, etiology, size, age, severity and the patient's desires. Goiato et al. [7] illustrated that nearly 5\% of all cancers affect mouth structures: the oropharynx, tongue, nasopharynx and larynx. After the removal of these lesions, problems relevant to speech, swallowing and chewing may emerge. Moreover, changes in psychosocial function, appearance, and vocational status may negatively affect the patients' quality of life after surgical intervention.

Beumer \& Marunick [8] clarified that the Surgical obturators may be classified as immediate and delayed surgical obturators. Daniel \& Vinod [9] explained that the defect may appear as a small opening caused by communication of the oral cavity into the maxillary sinus, or it may involve portions of the soft and hard palate, the floor of the nasal cavity and the alveolar ridge. A maxillary obturator was the name given by Danial \& Vinod [9] to the prosthesis constructed to repair the defect. Its placement rehabilitates oronasal separation to increase intraoral pressure and decrease nasal airflow rate.

According to Kanazawa et al. [10], obturators provide immediate enhancement in intelligibility and speech articulation, voice quality and swallowing that approximates pre-surgical function, enabling the patient to drink and eat immediately. Kanazawa [10] clarifies that obturator fabrication for edentulous patients is considered a major challenge due to lack of suction and support from the teeth. Therefore, Kornblith [11] said that the obturator prostheses must achieve certain functions such as protecting the wound or keeping the defective area clean, facilitating food, increasing trauma healing, promoting speech, and improving aesthetics, and helping the remodeling and rebuilding of the palatine contour.

Rodrigues \& Saldanha [6] suggested many different materials used for the fabricating of the hollow obturator. The first material is silicone rubber, which is advantageous in certain clinical 


\section{Juniper Online Journal of Case Studies}

situations, although it is porous in nature and has poor durability, requiring replacement on a regular basis. The second material is visible light-polymerized resin, but the maximal strength and long-term durability of these obturators have not been assessed yet. The third material is heat-processed acrylic resin, which is one of the most durable, tissue-compatible materials presently for the fabrication of the prosthesis.

\section{Case Report}

A 66-year-old male patient, diagnosed with malignant cancer of the maxilla, had undergone a partial maxillectomy and was referred to the Department of Prosthodontics, Near East University, Faculty of Dentistry, North Cyprus (Figure 1).

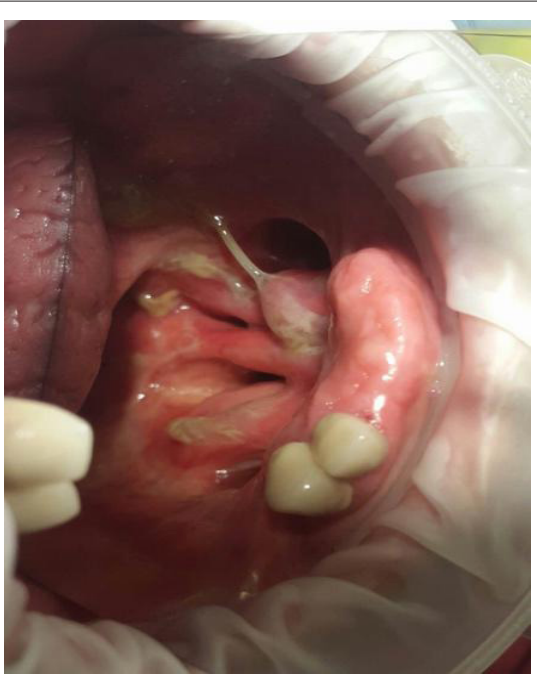

Figure 1: Intraoral anterior view of the maxillary anatomical defect.

On examination of the defect, it was noted that the partial maxillectomy was done and we found that the defect included hard and soft tissue of the maxilla, presence of anterior residual ridge (canine to canine) and tooth \#12,\#13. The patient had difficulty in speaking and could not eat or swallow properly. To minimize postoperative complications, the first prosthesis was placed. The second phase of treatment included an interim obturator. When the patient was examined four weeks later, the healing was satisfactory for the placement of the interim obturator. The interim obturator functional prosthesis facilitates proper healing. When the surgical site had completely healed (3-6 months postsurgically) a definite prosthesis was placed (Figure 2).

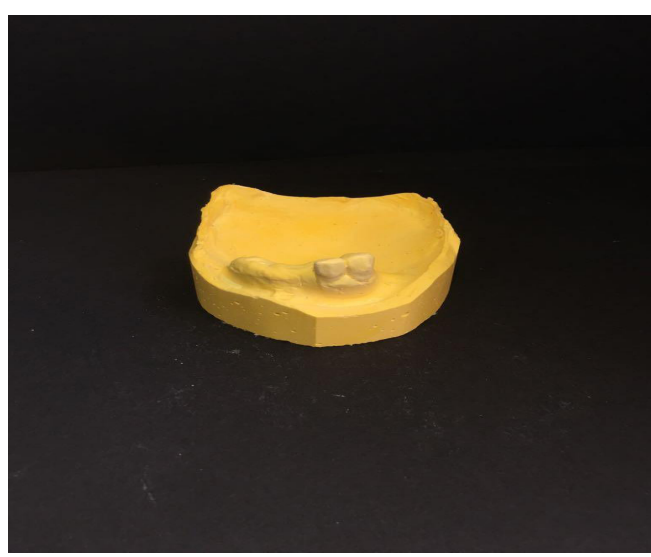

Figure 2: Primary cast.

It was decided to use a heat-polymerizing acrylic resin prosthesis, the expectations of this prosthesis were explained to the patient and to prevent any trauma to the underlying tissue, undercuts at the surgical site were blocked with vaselinized gauze. An irreversible hydrocolloid was used to make an impression of the defect area. The impression was removed and poured into a Type III dental stone and the final cast was obtained, on which a custom tray was made using a self-curing auto-polymerizing resin.

All undercuts on the cast were blocked out with plaster and wax. The final denture base and occlusal wax rims were prepared to record maxillomandibular relations. The record was articulated, and teeth arrangement was performed (Figure 3). All the undesired undercuts were blocked, jaw relation was recorded, and tooth arrangement was completed.
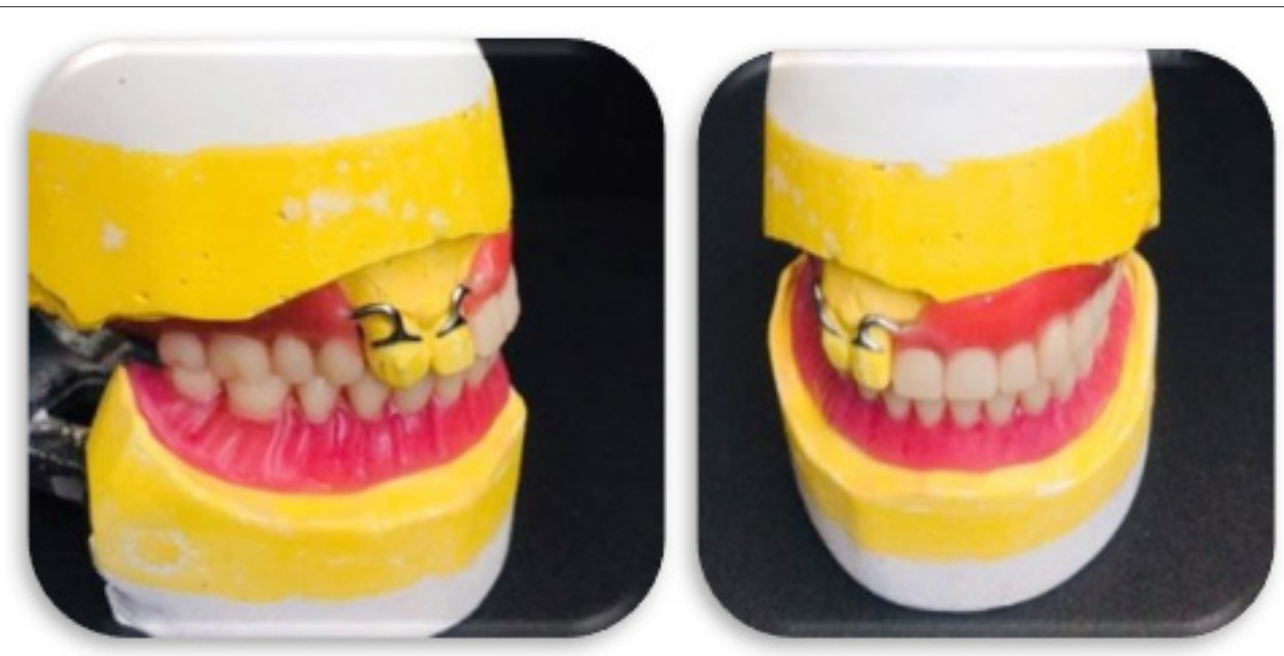

Figure 3: The record was articulated, and teeth arrangement was performed. 


\section{Juniper Online Journal of Case Studies}
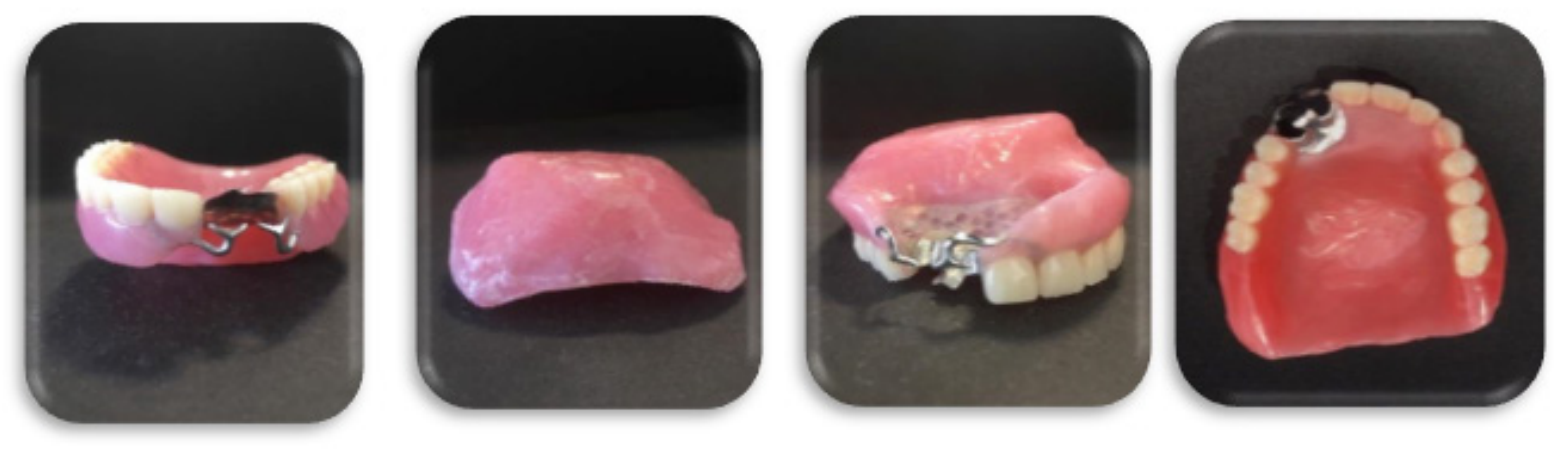

Figure 4: Extraoral view of the Obturator prosthesis.
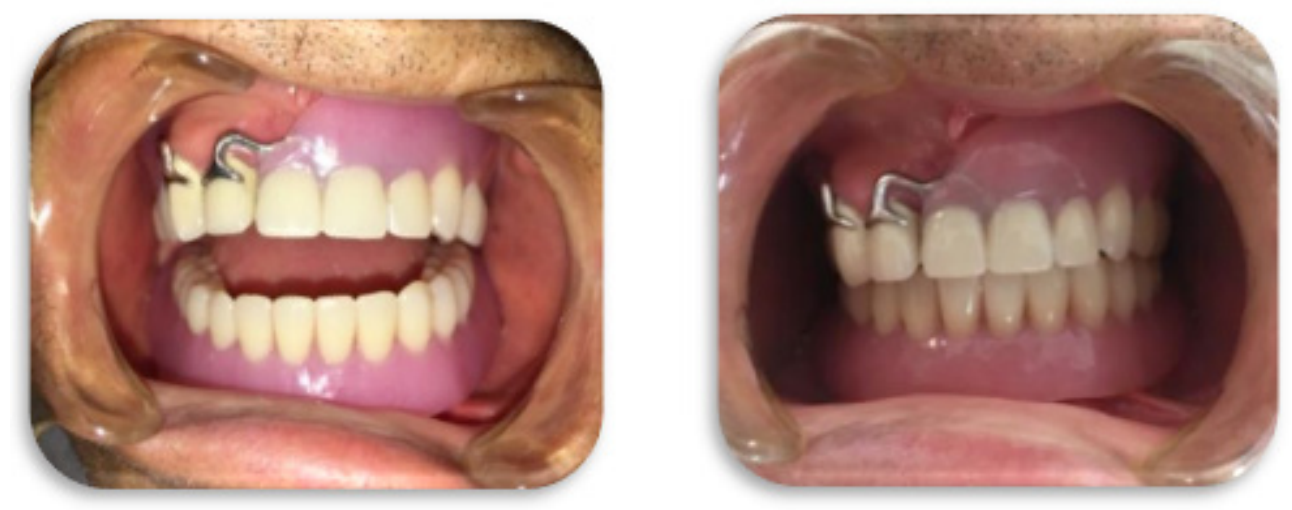

Figure 5: Intraoral view of the prosthesis Oral rehabilitation with an obturator removable partial dental prosthesis.

The pressure areas were relieved, and the peripheral seal of the prosthesis was tested by making the patient drink and eat without any resultant leakage into the nose. The prosthesis was delivered to the patient and he was instructed on home care and prosthesis maintenance (Figure $4 \& 5$ ). The patient was instructed to gently remove any exudates with a wet cotton tip soaked with a $5 \%$ Betadine solution and to clean the intaglio surface of the prosthesis once a day. Post treatment photographs showed a marked improvement of the patient in the aesthetics sense due to replacement of the missing teeth and the solution of the maxillary defect issue.

\section{Conclusion}

This clinical report describes a method for prosthetic rehabilitation of a patient with malignant cancer of the palate following partial maxillectomy. Maxillectomy, the total or partial removal of the maxilla, creates a challenging defect for the maxillofacial prosthodontist when attempting to provide an effective obturator. These findings suggest an obturator significantly contributes to improving the quality of life of maxillectomy patients.

The literature says, that both types of obturators allow for the fabrication of a lightweight prosthesis that is readily tolerated by the patient, while effectively closing the defect. In prosthetic treatment, the satisfaction of the patient is related to the dentist's psychological attitude in regard to gaining his confidence "but great understanding and cooperation on the patient's part is needed'.

\section{References}

1. Maureen S (2004) The expanding role of dental oncology in head and neck surgery. Surg Oncol Clin N Am 13(1): 37-46.

2. Kanatas AN, Rogers SN (2010) A systematic review of patient self-completed questionnaires suitable for oral and maxillofacial surgery. Br J Oral Maxillofac Surg 48(8): 579-590.

3. Fialka Moser V, Crevenna R, Korpan M, Quittan M (2003) Cancer rehabilitation: particularly with aspects on physical impairments. J Rehabil Med 35(4): 153-162.

4. Keyf F (2001) Obturator prostheses for hemimaxillectomy patients. J Oral Rehabil 28(9): 821-829.

5. McGregor IA, McGregor FM (1986) Cancer of the face and mouth: pathology and management for surgeons. Churchill Livingstone, London, United Kingdom.

6. Rodrigues SJ, Saldanha S (2011) Prosthetic rehabilitation of a patient after partial maxillectomy: A clinical report. Contemp Clin Dent 2(4): 355-358.

7. Goiato MC, Pesqueira AA, Ramos da Silva C, Gennari Filho H, Micheline Dos Santos D (2009) Patient satisfaction with maxillofacial prosthesis. Literature review. J Plast Reconstr Aesthet Surg 62(2): 175-180.

8. Beumer J, Curtis TA, Marunick MT (1996) Maxillofacial rehabilitation: prosthodontic and surgical considerations. In: Beumer J, Curtis TA, Marunick MT (Eds.), ( $1^{\text {st }}$ edn), Ishiyaku Euroamerica Inc, USA. 
9. Daniel AY, Vinod B (2015) Prosthetic rehabilitation of the dentate maxillectomy patient from a delayed surgical to an interim obturator: A clinical case report. CHRISMED Journal of Health and Research 2(1): 68.

10. Kanazawa T, Yoshida H, Furuya Y, Shimodaira K (2000) Sectional prosthesis with hollow obturator portion made of thin silicone layer over resin frame. J Oral Rehabil 27(9): 760-764.
11. Kornblith AB, Zlotolow IM, Gooen J, Huryn JM, Lerner T, et al. (1996) Quality of life of maxillectomy patients using an obturator prosthesis. Head Neck 18(4): 323-334.

DOI: 10.19080/JOJCS.2019.09.555769

Your next submission with Juniper Publishers
will reach you the below assets
- Quality Editorial service
- Swift Peer Review
- Reprints availability
- E-prints Service
- Manuscript Podcast for convenient understanding
- Global attainment for your research
- Manuscript accessibility in different formats
( Pdf, E-pub, Full Text, Audio)
- Unceasing customer service
Track the below URL for one-step submission
https://juniperpublishers.com/online-submission.php

